\title{
Diagnostic performance of several biomarkers for identification of cases of non-communicable diseases among Central Africans
}

Charles Bitamazire Businge ${ }^{1},{ }^{*}$ Benjamin Longo-Mbenza $^{1}$, ${ }^{*}$ Oladele Vincent Adeniyi ${ }^{2}$, Moise Mvitu Muaka ${ }^{3}$, Georges Mvumbi Lelo ${ }^{4}$, Mireille Solange Nganga Nkanga ${ }^{4}$, Jean-Marie Kavembe ${ }^{4}$, Baudoin Buassa-bu-Tsumbu ${ }^{4}$, Jean-Rene' M'buyamba Kabangu', Daniel Ter Goon ${ }^{5}$

1. Walter Sisulu University, Faculty of Health Sciences, Mthatha, South Africa.

2. Walter Sisulu University, Faculty of Health Sciences, East London, South Africa.

3. University of Kinshasa, Retinal Surgery Unit, DR Congo.

4. University of Kinshasa, Faculty of Medicine, DR Congo.

5. Faculty of Health Sciences, University of Fort Hare, East London, South Africa.

\section{Author details:}

Charles Bitamazire Businge: E-mail: cbusingae@gmail.com, Moise Mvitu Muaka: E-mail: moisemvitu2001@gmail.com, Georges Mvumbi Lelo: E-mail: mvumbilelo@yahoo.fr, Mireille Solange Nganga Nkanga: E-mail: mnganga2002@yahoo.fr, Jean-Marie Kavembe: E-mail: dr12jmkayembe@yahoo.com, Buassa-bu-Tsumbu: E-mail: baudouin_buassa@yahoo.com, Jean-Rene’ M’buyamba Kabangu: E-mail: jerembu@yahoo.fr, Daniel Ter Goon: E-mail: dgoon@ufh.ac.za

\begin{abstract}
Background: This study determined the diagnostic performance of new biomarkers for a composite diagnosis of non-communicable diseases (NCDs) among Central Africans.

Methods: This case-control study was conducted at LOMO Medical Centre, Kinshasa, DR Congo (DRC) between January - December, 2008. The cases comprised 226 participants with concurrent presence of at least 2 or more of NCDs. Anthropometric parameters and blood pressure were measured while blood samples were assayed for biomarkers. The receiver operating characteristics curve and the logistic regression model were applied.

Results: Serum selenium (Se) had specificity and sensitivity of $72.4 \%$ and $91.1 \%$, respectively with an area under the curve (AUC) of 0.802; Nitric oxide (NO) (specificity: 72.4\%; sensitivity: 93.0\%) (AUC =0.800); Thyroid stimulating hormone (TSH) levels $>6 \mathrm{Mu} / \mathrm{L}$ (specificity: $75 \%$; sensitivity: $65 \%$ ) (AUC $=0.0 .727$ ); serum calcium levels of $\geq 110 \mathrm{~g} / \mathrm{L}$ (specificity: $76 \%$; sensitivity: $75 \%$ ) (AUC = 0.822); and daily salt intake of $\geq 10 \mathrm{~g} /$ day (specificity: $75 \%$; sensitivity: $67 \%$ ) (AUC $=0.653$ ) in the diagnosis of all NCDs, which were all highly significant $(<0.0001)$.

Conclusion: Serum Se, NO, calcium, TSH and daily salt intake had high diagnostic performance as biomarkers for identification of patients with concurrent NCDs in the study population.

Keywords: Non-communicable diseases, diet, new biomarkers, Central Africa.

DOI: https://dx.doi.org/10.4314/ahs.v18i4.9

Cite as: Businge CB, Longo-Mbenza B, Adeniyi OV, Muaka MM, Lelo GM, Nkanga MSN, Kavembe J-M, Buassa-bu-Tsumbu B, Kabangu J-R M, Ter Goon D. Diagnostic performance of several biomarkers for identification of cases of non-communicable diseases among Central Africans. Afri Health Sci. 2018;18(4): 909-916. bttps:// dx.doi.org/10.4314/abs.v18i4.9
\end{abstract}

\section{Corresponding authors:}

Benjamin Longo-Mbenza,

Walter Sisulu University, Faculty of Health Sciences, Private Bag X1, Mthatha, 5117 Eastern Cape, South Africa:

Tel: +27732822843; Fax: +27475022101

Email: longombenza@gmail.com

Or

Oladele Vincent Adeniyi,

Walter Sisulu University, Faculty of Health Sciences,

East London, South Africa 5200

Tel: +27793110232; +27437082351

Email: vincoladele@gmail.com

\section{Introduction}

Worldwide, there is a shift from disease patterns associated with infections and nutritional deficiency towards non-communicable diseases. This new pattern of diseases is associated with economic development and aging populations, but is made worse by rapid rural to urban migration and globalization. ${ }^{1,2}$ This change is rapidly spreading throughout sub-Saharan Africa and is partially mediated by the nutritional transition characterised by consumption of higher calorie food stuffs and a more sedentary lifestyle following rural to urban migration. 
Furthermore, adoption of behaviours such as smoking and excessive alcohol consumption in addition to changes in dietary habits due to globalisation are associated with an increased incidence of non-communicable diseases. ${ }^{1,2}$ The emergent NCDs have shared risk factors, which may suggest a common patho-physiological pathway, paving the way for screening of several sub-clinical NCDs using one biomarker. ${ }^{2,3}$

Biomarkers with high sensitivity and specificity are not only useful in screening the general population for sub-clinical diseases which require further diagnostic tests, but can be of great value in predicting the prognosis in those diagnosed with clinical and subclinical diseases. ${ }^{4,5}$ However, information about diagnostic biomarkers for screening non-communicable diseases in Kinshasa, Democratic Republic of Congo (DRC) is lacking. The study aimed to determine the diagnostic performance of various biomarkers for a composite diagnosis of all NCDs (the presence of 2 or more of the following clinical conditions: Type 2 diabetes, stroke, myocardial infarction, hypertension, and cancer) among participants in Kinshasa Province, Democratic Republic of Congo.

\section{Methods}

\section{Study design and participants}

We conducted a case - control study involving 226 cases and 226 controls (1 Case: 1 Control) from January to December 2008 at LOMO Medical Centre, Kinshasa, DR Congo (DRC). The cases were participants with concurrent presence of at least 2 or more of; type 2 diabetes mellitus (T2DM), stroke, myocardial infarction, hypertension, and cancers at defining NCDs without tobacco use or excessive alcohol intake by participants. The controls were selected out of 2260 apparently healthy individuals visiting their parents and friends as in-patients during the study period and at the study setting. A random sample of $10 \%(n=226)$ was selected as eligible controls matched to cases for sex, age, ethnicity, post - rural urban migration, and residence in Kinshasa province for at least five years. However, 174 controls (response rate $=77 \%$ ) effectively participated in the study without the fore mentioned diagnoses, tobacco use, excessive alcohol intake, pregnancy, and lactation.

\section{Ethical consideration}

The Ethics Committee, School of Public Health (University of Kinshasa), granted the approval for this study. Administrative permission was also obtained from the Head of Department of Clinical Biology. Each participant signed a written, informed consent after receiving detailed information on the purpose of the study.

\section{Study procedure}

Eligible participants were examined after fasting for at least 8 hours and disclosure identity in terms of sex and age, and amount of salt intake daily. Trained nurses measured height, weight, waist circumference (WC), systolic blood pressure (SBP), and diastolic blood pressure (DBP) according to standardized protocols. Certified sonographer (BLM) examined the carotid artery B - mode ultrasound imaging using a Biosound Phase (Biosound Inc, Indianopolis, USA), a device equipped with a annular array probe of $7.5 \mathrm{Mhz}$. Carotid Intima - media thickness (cIMT) was measured at near and far wall interfaces of internal and external carotid arteries.

Blood (total, serum and plasma) samples were assayed immediately to measure concentrations of erythrocyte sedimentation (ESR), haemoglobin, CD4 count, high density cholesterol (HDL), total cholesterol, triglycerides, low density lipoprotein (LDL), oxidized low density lipoprotein (oxLDL), cortisol, C - peptide, glucose, C - reactive protein (CRP), insulin, calcium, $\mathrm{D}$ - dimer, nitrous oxide (NO), thyroid stimulating hormone (TSH), and immunoglobulin $\mathrm{G}(\mathrm{IgG})$ against Helicobacter pylori(Hp). Homeostasis - insulin resistance index (HOMA - IR) was calculated using fasting glucose and insulin.

Laboratory data were obtained using calibrated and standard routine procedures and specific protocols of manufacturers' suchmetric Sensor as CyFlowR Counter (Partec GmH, Munster, Germany), Hydrasys system (Serbia, Evry, France), spectrophotomer Hospital Diagnostics (Florence, Italy), kits of Biome'rieux (Marcy l'Etoile, France) and Mercodia AB (Silveniusgatan 8 A, SE754, Uppsala, Sweden, and a caloric Sensor Hach DR/2010 spectophotomer (HACH, USA). The Hach DR/2010 was ideal for both field and mobile laboratory use since it is portable, operating from either battery or line power. An Orion model 801 microprocessor ionalyzer was used to lead SIE testing. 


\section{Definitions}

The physical data were structural markers such as WC and cIMT for metabolic syndrome (MS) and atherosclerosis, respectively. Laboratory data were biomarkers to define the following diseases and syndromes (constellation or clusters): ESR and IgG against Hp for infections, insulin resistance, MS, and atherosclerosis; haemoglobin for nutritional status, sickle cell disease, anaemia, endemic infections, heart failure, and chronic kidney disease; CD4 for immunity; triglycerides, total cholesterol, HDL, LDL, glucose, $\mathrm{C}$ - peptide, uric acid, and HOMA - IR for dyslipidemia, hypertension, diabetes mellitus, MS, insulin resistance, and atherosclerosis; NO for endothelial dysfunction; D - dimer for MS and hypercoagulability; CRP for inflammation, infections, and cytokines; Se deficiency key trace element in nutrition and oxLDL for oxidative stress imbalance and atherosclerosis; Cortisol for distress hormone; TSH for iodine nutrition and thyroid hormones; and calcium for cancers, atherosclerosis, and vitamin D. Electrocardiograms, X-ray features, enzymes, coronary angiograms, ultrasound and histological studies confirmed the presence and absence of NCDs.

\section{Statistical analysis}

For univariate descriptive statistics, data were presented as count (frequency $=$ number $=\mathrm{n}$ ) and proportions $(\%)$ for categorical variables and means \pm standard deviations (SD) for continuous variables normally distributed. The diagnostic performance cut-off values of various biomarkers at discriminating NCDs and controls were tested a posteriori, using the receiver operating characteristic curve (ROC) method. The areas under the curve (AUC for c- static) were calculated with the corresponding Standard Error and 95\% CI (Figure 1-2). Multivariate analysis was applied to establish the independent predictors of NCDs that could potentially be used to identify individuals at high risk of developing incident NCDs. A p-value of $<0.05$ was considered as statistically significant. All statistical analyses were performed using Statistical Package for Social Sciences (SPSS version 23) for Windows (New York, USA).

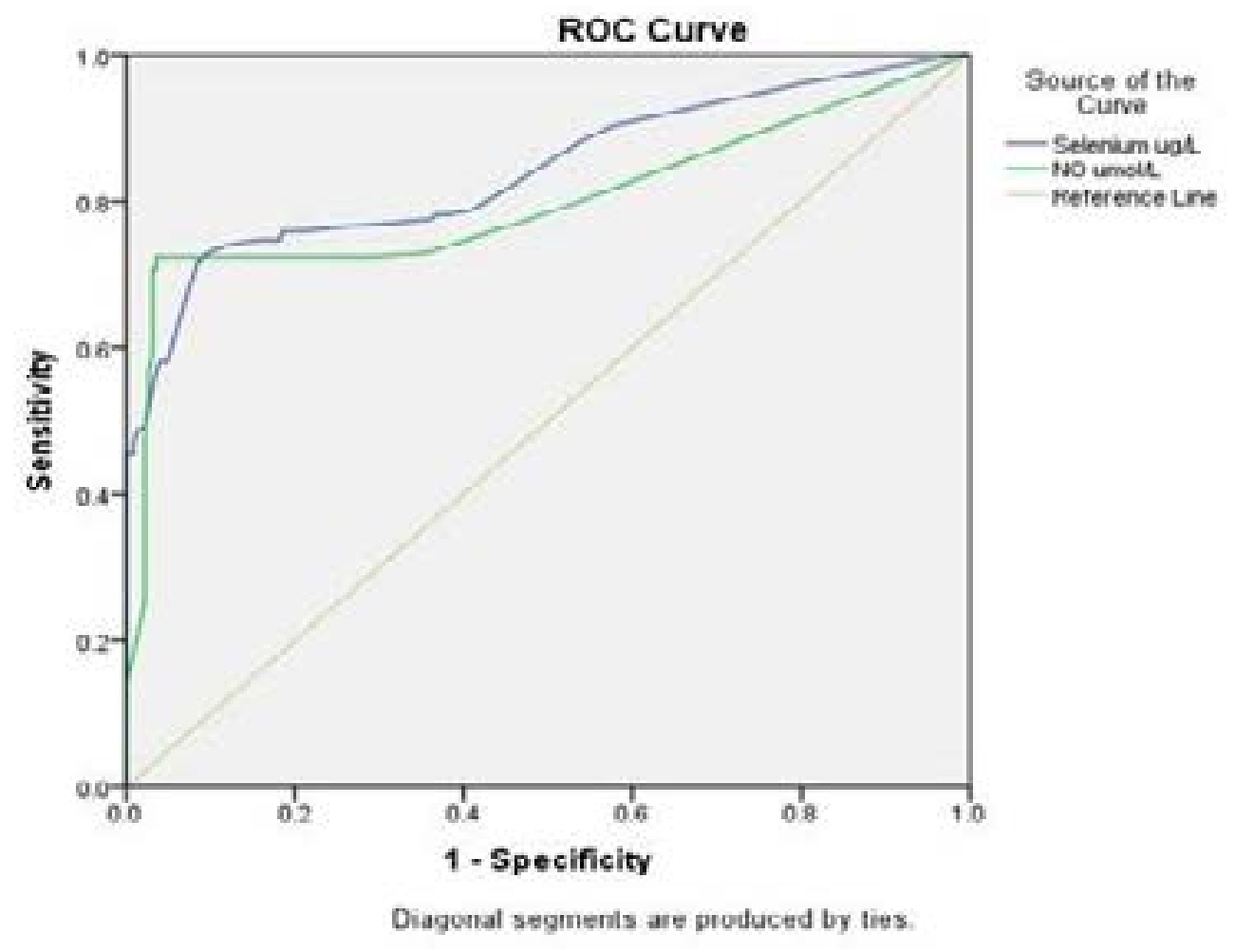

Figure 1. ROC curves showing the sensitivity and specificity of Se and NO for all NCDs 


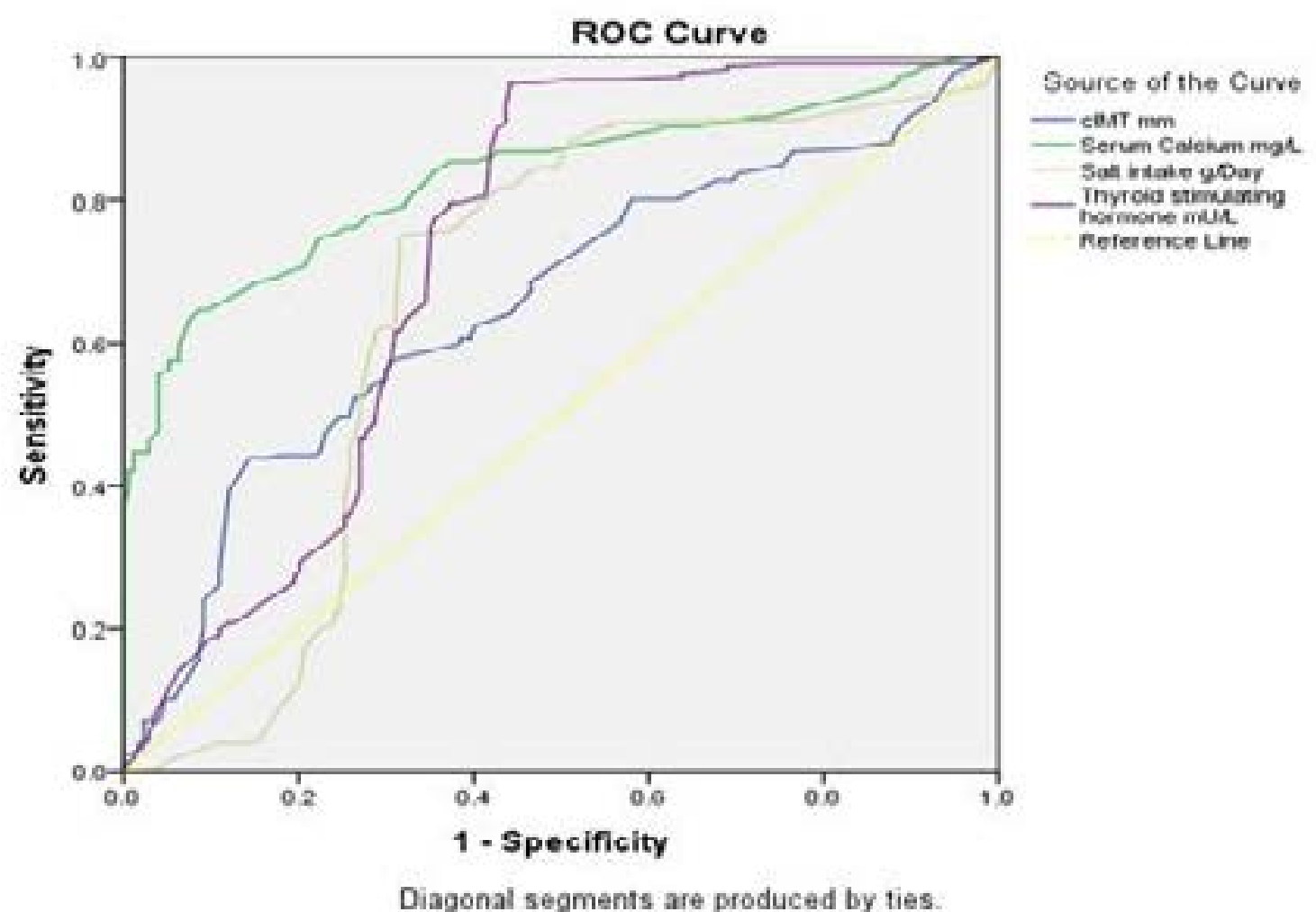

Figure 2. ROC curves showing the sensitivity and specificity of various diagnostic biomarkers for all NCDs

\section{Results}

Participants' mean age was $65.6 \pm 11.5$ years (range $27-$ 84). The cases comprised of 116 males and 110 females (mean age $64.8 \pm 11.7$ years), while controls were 84 males and 90 females (mean age $66.6 \pm 11.2$ years). Shown in Table 1 are the biomarkers' definition of NCDs. Apart from ESR $(p=0.961)$ and salt intake $(p=0.077)$, all others biomarkers were highly significant between the cases and the controls. 
Table 1: Biomarkers of non-communicable diseases

\begin{tabular}{|c|c|c|c|c|}
\hline Biomarkers & $\begin{array}{l}\text { Cases } \\
(\text { Mean } \pm \text { SD) }\end{array}$ & $\begin{array}{l}\text { Controls } \\
(\text { Mean } \pm \text { SD) }\end{array}$ & F-ratio & $\mathrm{p}$-value \\
\hline HDL-C (mg/dL) & $24.86 \pm 2.066$ & $50.67 \pm 2.82$ & 56.924 & $<0.0001$ \\
\hline LDL-C (mg/dL) & $128.15 \pm 2.89$ & $98.21 \pm 3.03$ & 49.919 & $<0.0001$ \\
\hline Triglycerides $(\mathrm{mg} / \mathrm{dL})$ & $147.73 \pm 2.89$ & $109.94 \pm 4.30$ & 36.909 & $<0.0001$ \\
\hline Waist circumference $(\mathrm{cm})$ & $84.30 \pm 0.87$ & $74.06 \pm 0.53$ & 87.678 & $<0.0001$ \\
\hline $\mathrm{SPB}(\mathrm{mmHg})$ & $137.77 \pm 2.25$ & $116.64 \pm 0.70$ & 63.946 & $<0.0001$ \\
\hline $\mathrm{DBP}(\mathrm{mmHg})$ & $77.07 \pm 0.98$ & $68.99 \pm 0.80$ & 36.477 & $<0.0001$ \\
\hline Total cholesterol (mg/dL) & $166.96 \pm 4.25$ & $140.93 \pm 4.81$ & 16.405 & $<0.0001$ \\
\hline Uric acid $(\mathrm{mg} / \mathrm{dL})$ & $6.20 \pm 0.20$ & $4.73 \pm 0.13$ & 32.801 & $<0.0001$ \\
\hline Fasting plasma glucose $(\mathrm{mg} / \mathrm{dl})$ & $198.54 \pm 8.66$ & $94.98 \pm 1.16$ & 108.882 & $<0.0001$ \\
\hline Selenium $(\mu \mathrm{g} / \mathrm{L})$ & $17.95 \pm 0.91$ & $78.40 \pm 4.33$ & 325.357 & $<0.0001$ \\
\hline ESR (mm/ $1^{\text {st }}$ Hour) & $51.89 \pm 1.67$ & $52.02 \pm 2.0$ & 0.002 & 0.961 \\
\hline Nitric oxide $(\mu \mathrm{mol} / \mathrm{dL})$ & $5.23 \pm 0.46$ & $25.89 \pm 1.37$ & 248.293 & $<0.0001$ \\
\hline IgG anti-Helicobacter pylori & $100.8 \pm 4.97$ & $75.11 \pm 4.40$ & 13.278 & $<0.0001$ \\
\hline Oxidised LDL (iU/L) & $176.29 \pm 4.90$ & $80.78 \pm 6.40$ & 145.929 & $<0.0001$ \\
\hline CD4 count $($ Cells $/ \mu \mathrm{L})$ & $396.23 \pm 10.83$ & $908.05 \pm 29.00$ & 327.514 & $<0.0001$ \\
\hline $\mathrm{D}$-dimer $(\mathrm{ng} / \mathrm{mL})$ & $2119.41 \pm 152.97$ & $491.51 \pm 27.03$ & 85.554 & $<0.0001$ \\
\hline $\mathrm{CRP}(\mathrm{mg} / \mathrm{dL})$ & $4.7 \pm 1.24$ & $2.1 \pm 0.9$ & $2.41 \pm 1.3$ & $<0.0001$ \\
\hline cIMT (mm) & $0.685 \pm 0.025$ & $0.487 \pm 0.024$ & 31.588 & $<0.0001$ \\
\hline Serum calcium $(\mathrm{mg} / \mathrm{L})$ & $140.01 \pm 3.07$ & $89.90 \pm 1.84$ & 168.871 & $<0.0001$ \\
\hline Salt intake (g/Day) & $13.39 \pm 0.433$ & $12.00 \pm 0.70$ & 3.134 & 0.077 \\
\hline Haemoglobin (mg/Dl) & $10.50 \pm 2.43$ & $12.01 \pm 2.94$ & 31.976 & $<0.0001$ \\
\hline Cortisol & $23.39 \pm 0.76$ & $19.55 \pm 0.80$ & 11.765 & $<0.0001$ \\
\hline Fasting C-peptide $(\mu \mathrm{g} / \mathrm{L})$ & $2.61 \pm 0.13$ & $1.37 \pm 0.03$ & 67.204 & $<0.0001$ \\
\hline HOMA-IR Index & $12.62 \pm 0.76$ & $8.19 \pm 0.50$ & 136.939 & $<0.0001$ \\
\hline $\mathrm{TSH}(\mathrm{miU} / \mathrm{L})$ & $4.30 \pm 0.12$ & $2.40 \pm 0.19$ & 76.569 & $<0.0001$ \\
\hline
\end{tabular}

$\mathrm{ESR}=$ Erythrocytesedimentation; HDL-C $=$ High density lipoprotein cholesterol; LDL-C=low density lipoprotein; oxLDL=Oxidized low density lipoprotein; $\mathrm{CRP}=\mathrm{C}-$ reactive protein; $\mathrm{NO}=$ Nitrous oxide; $\mathrm{TSH}=$ Thyroid stimulating hormone; IgG=Immunoglobulin G; Hp=Helicobacter pylori; HOMA-IR= Homeostasis - insulin resistance index; cIMT $=$ Carotid Intima - media thickness

Shown in Table 2 is the area under the curve for various diagnostic markers of all NCDs, while the sensitivity and specificity of various diagnostic biomarkers for all NCDs is presented in Table 3. Serum selenium had specificity and sensitivity of $72.4 \%$ and $91.1 \%$, with an area under the curve (AUC) of 0.802; Nitric oxide (specificity: 72.4\%; sensitivity: 93.0\%) (AUC $=0.800)$; TSH levels
$>6 \mathrm{Mu} / \mathrm{L}$ (specificity: 75\%; sensitivity: 65\%) (AUC $=$ 0.0 .727 ); serum calcium levels of $\geq 110 \mathrm{~g} / \mathrm{L}$ (specificity: $76 \%$; sensitivity: $75 \%$ ) (AUC $=0.822$ ); and daily salt intake of $\geq 10 \mathrm{~g} /$ day (specificity: $75 \%$; sensitivity: $67 \%$ ) $(\mathrm{AUC}=0.653)$ in the diagnosis of all NCDs, which were all highly significant $(<0.0001)$.

Table 2: Sensitivity and specificity of various diagnostic biomarkers for all NCDs

\begin{tabular}{llll}
\hline Biomarkers & Cut off limit & Sensitivity & Specificity \\
\hline Serum selenium $(\mathrm{mg} / \mathrm{dL}$ & $<35$ & $72.4 \%$ & $91.1 \%$ \\
Nitric oxide $(\mu \mathrm{mol} / \mathrm{dL})$ & $<10$ & $72.4 \%$ & $93.0 \%$ \\
cIMT $(\mathrm{mm})$ & $>0.50$ & $60.0 \%$ & $61.0 \%$ \\
Serum calcium $(\mathrm{mg} / \mathrm{dL})$ & $>110$ & $76.1 \%$ & $75.0 \%$ \\
Salt intake $(\mathrm{g} / \mathrm{day})$ & $>10$ & $75.0 \%$ & $67.0 \%$ \\
TSH $(\mathrm{mU} / \mathrm{mL})$ & $>6$ & $74.8 \%$ & $65.0 \%$ \\
CD4 $($ cells/mL) & $<500$ & $76.4 \%$ & $85.0 \%$ \\
\hline
\end{tabular}

cIMT=Carotid Intima - media thickness; TSH=Thyroid stimulating hormone 
Table 3: Area under the curve for various diagnostic markers of all NCDs

\begin{tabular}{lllll}
\hline Biomarkers & AUC & SE & $95 \%$ CI & p-value \\
\hline CD4 $($ cells/mL) & 0.900 & 0.015 & $0.871-0.930$ & $<0.0001$ \\
Serum calcium $(\mathrm{mg} / \mathrm{dL}$ & 0.822 & 0.020 & $0.793-0.872$ & $<0.0001$ \\
Serum selenium $(\mathrm{mg} / \mathrm{dL}$ & 0.802 & 0.021 & $0.800-0.833$ & $<0.0001$ \\
Nitric oxide $(\mu \mathrm{mol} / \mathrm{dL})$ & 0.800 & 0.025 & $0.750-0.849$ & $<0.0001$ \\
TSH $(\mathrm{mU} / \mathrm{mL})$ & 0.727 & 0.028 & $0.672-0.781$ & $<0.0001$ \\
Salt intake $(\mathrm{g} / \mathrm{day})$ & 0.661 & 0.030 & $0.601-0.721$ & $<0.0001$ \\
cIMT $(\mathrm{mm})$ & 0.653 & 0.028 & $0.599-0.707$ & $<0.0001$ \\
\hline
\end{tabular}

$\mathrm{TSH}=$ Thyroid stimulating hormone; cIMT=Carotid Intima - media thickness

\section{Discussion}

In the current study, serum selenium $\leq 35 \mu \mathrm{g} / \mathrm{L}$ had specificity and sensitivity of $72.4 \%$ and $91.1 \%$, respectively, for identifying cases of NCDs. Se deficiency alone rarely leads to clinical manifestation, but in association with other factors, exacerbates disease manifestation. ${ }^{6,7}$ Normal physiological reactions usually generate oxygen and nitrogen reactive species which are quickly neutralised by endogenous anti-oxidants such as the selenium dependent glutathione. ${ }^{8}$ The most basic oxidant molecules are superoxide and its metabolite hydrogen peroxide $\left(\mathrm{H}_{2} \mathrm{O}_{2}\right)$, which are produced from $1-4 \%$ of the inspired oxygen by the normal physiological activities of energy producing mitochondria, metabolic function of the endoplasmic reticulum, and defensive/ inflammatory role of lysosomes and other cellular organelles ${ }^{13}$. In selenium deficiency, there is diminished glutathione peroxidase anti-oxidant capacity, accumulation of superoxide and hydrogen peroxide and lipid peroxides with resultant oxidative damage to structural proteins and lipids, enzymatic and repair proteins, signalling molecules and DNA predisposing to progressive multi-organ damage, increased risk of chronic degenerative diseases and malignancy.

The present study indicates that NO is one of the biomarkers with high diagnostic performance for all NCDs among the study population with an area under the curve of 0.800 , and sensitivity and specificity of $72.4 \%$ and $93.0 \%$, respectively. Nitric oxide is an endogenous mediator of several physiological processes which include vasorelaxation, macrophage activation, gene expression and apoptosis and it is one of the most prominent vasculo-protective molecules. ${ }^{9}$ In the presence of increased superoxide concentration, nitric oxide is quickly oxidised to the more potent oxidant stress molecule peroxynitrite (ONOO-) which is associated with endothelial dysfunction and activation; increased intima-media thickness, an early marker of atherosclerosis and cardiovascular disease; nitrosylation of proteins and oxidative damage to DNA and cell cycle regulator proteins. ${ }^{10}$

The findings of this present study indicate that TSH levels $>6 \mathrm{Mu} / \mathrm{L}$ had a specificity and sensitivity of $75 \%$ and $65 \%$ respectively, in diagnosing all NCDs. TSH was significantly higher among cases of NCDs than controls despite no difference in mean T3 and T4 (data not shown) suggesting subclinical hypothyroidism among cases. With nearly 2 billion people having inadequate iodine in their diet globally, ${ }^{11}$ iodine deficiency is likely to be the main cause of hypothyroidism and may be the main underlying cause in the study population given endemic iodine deficiency in DRC. ${ }^{12}$ A significant proportion of the population in DRC, with inadequate iodine supplementation and concurrent consumption of goitregenic diet, may be prone to sub-clinical hypothyroidism and chronically elevated TSH. TSH activity in the thyroid gland leads to NADPH oxidation by NADPH oxidase producing NADP and superoxide radicals. The superoxide radicals are then converted to the less potent $\mathrm{H}_{2} \mathrm{O}_{2}$, by superoxide dismutase, a selenium-dependent enzyme. $\mathrm{H} 2 \mathrm{O} 2$ that is not used up in this process is neutralized by selenium-dependent glutathione peroxidase. ${ }^{13}$ Also, the reduced bioavailability of NO results in chronic elevation of TSH. This in turn, leads to increased circulating levels of LDC-C and thus, reduced function of hepatic LDL receptors. Chronic inflammation is then mediated by higher 
circulating levels of TNF $\alpha$ and IL- $6 .{ }^{14-16}$ This results in reduced endothelial mediated vasodilation and increased intima-media thickness in the systemic circulation, an early marker of atherosclerosis and therefore, a herald of multiple organ failure. ${ }^{17}$ Elevated TSH is a risk factor for increased cardiovascular disease mortality among men $<$ 50 years and women $>60 .{ }^{18,19}$ Iodine deficiency is not only one of the leading causes of hypothyroidism ${ }^{15}$, but it also accounts for marked reduction in exogenous anti-oxidant capacity as iodine is three times a more potent anti-oxidant than Vitamin C and is concentrated in several body organs such as the eye, thyroid, prostate, breast and gut, where it may have a crucial protective effect against oxidant molecules. ${ }^{20}$

In this current study, serum calcium levels $\geq 110 \mathrm{~g} / \mathrm{L}$ had a sensitivity and specificity of $76 \%$ and $75 \%$ in the diagnosis of all NCDs. Therefore, in the absence of elevated PTH, underlying malignancy should be ruled out in all individuals presenting with hypercalcaemia. Although hypercalcaemia did not feature as an independent determinant of NCDs, it features as an important biomarker with high sensitivity and specificity for diagnosis of all NCDs. Primary hyperparathyroidism and malignancy account for about $90 \%$ of all cases of hypercalcaemia making malignancy the second highest cause of hypercalcemia in adults. ${ }^{21}$ Although hypercalcaemia is one of the earliest manifestation of malignancy, it is usually asymptomatic until serum levels are $\geq 120 \mathrm{~g} / \mathrm{L}$. It is an early marker of several underlying malignancies, particularly, squamous cell carcinoma of the lung, lymphomas. This is due to humoral hypercalcemia of malignancy, mainly caused by overproduction of PTH related protein (PTHrP) especially prevalent in lung cancer, cancers of the head and neck, skin, esophagus, breast, genitourinary tract, multiple myeloma, and lymphoma. ${ }^{21,22}$

The finding of this present study indicates that a daily salt intake of $\geq 10 \mathrm{~g} /$ day had $75 \%$ and $67 \%$ sensitivity and specificity, respectively, as a diagnostic marker for all NCD. Additionally, both cases and controls had comparable average daily salt intake, which is more than twice the recommended average of $6 \mathrm{~g} /$ day $(13.39 \pm 0.433 \mathrm{~g} /$ day for cases and $12.00 \pm 0.70$ for controls $(p=0.077) .^{23,24} \mathrm{~A}$ high salt intake is a risk factor for hypertension, cardiovascular disease and kidney injury. ${ }^{25}$

\section{Conclusion}

Serum Se, NO, Calcium, TSH, $\mathrm{CD}^{+}$count, cIMT and daily salt intake had high diagnostic performance as biomarkers for identification of patients with concurrent NCDs in the study population. This provides an opportunity for integrated screening for all NCDs using one or a combination of a few of these biomarkers.

\section{Conflict of interest}

None.

\section{References}

1. Omran A. The epidemiologic transition. A theory of the Epidemiology of population change. Bull World Health Organ. 2001;79(2):161-170.

2. Popkin B. Dynamics of the nutrition transition and its implications for the developing world. Forum Nutr. 2003; 56:262-264. PubMed.

3. Bourne LT, Lambert EV, Steyn K. Where does the black population of South Africa stand on the nutrition transition? Public Health Nutri. 2002;5(1A):157-162.

4. Qin C, Tao L, Phang YH et al. The assessment of the readiness of molecular biomarker-based mobile health technologies for healthcare applications. Sci Rep. 2015;5:17854. PubMed. DOI: 10.1038/srep17854.

5. Huang H, Ideh RC, Gitau E et al. Discovery and validation of biomarkers to guide clinical management of pneumonia in African children. Clin Infect Dis. 2014; 58(12):1707-15.

6. Contempre B, Morreale de Escobar G, Denef J, Dumont JE, Many M-C. Thiocyanate overload and thyroid necrosis. Endocrinology, [online], 2003. Available from: doi:10.1210/en.2003-0886. Downloaded 03/08/2016.

7. Peters U, Foster CB, Chatterjee N, Schatzkin A et al. Serum selenium and risk of prostate cancer-a nested case-control study. Am J Clin Nutr. 2007;85:209-17.

8. Valadez-Vega C, Delgado-Olivares L, González JAM et al. The role of natural antioxidants in cancer disease in oxidative stress and chronic degenerative diseases. (JA Morales-Gonzalez, Ed). In Tech: Rijeka, Croatia, 2013; p391-418. [On line]. Available from: http://dx.doi. org $/ 10.5772 / 51503$.

9. Lazo-de-la-Vega-MonroyM, Fernández-Mejía C. Oxidative stress in diabetes mellitus and the role of vitamins with antioxidant actions. [Online], 2013; Available from: http://dx.doi.org/10.5772/51788. Downloaded 01/09/2016.

African Health Sciences Vol 18 Issue 4, December, 2018 
10. Johansen JS, Harris AK, Rychly DJ, Ergul A. Oxidative stress and the use of antioxidants in diabetes: Linking basic science to clinical practice. Cardiovas Diabetol. 2005;4(1):5.

11. Anderson M, Karumbunathan V, Zimmermann MB. Global iodine status in 2011 and trends over the past decade. J. Nutri. 2012;142: 744-750. PubMed.

12. Ngo DB, Dikassa L, Okitolonda W et al. Selenium status in pregnant women of rural population (Zaire) in relationship to iodine deficiency. Trop Med Int Health. 1997;2:572-581.

13. Smyth PP. Role of iodine in antioxidant defence in thyroid and breast disease. Biofactors, 2003;19(3-4):121-30. 14. Dardano A, Ghiadoni L, Plantinga Y et al. Recombinant human thyrotropin reduces endothelium-dependent vasodilation in patients monitored for differentiated thyroid carcinoma. J Clin Endocrinol. Metab. 2006;91: 41754178. PubMed.

15. Antunes TT, Gagnon AM, Bell A, Sorisky A. Thyroid-stimulating hormone stimulates interleukin- 6 release from 3T3-L1 adipocytes through a cAMP-protein kinase: A pathway. Obes Res. 2005;13:2066-2071. PubMed.

16. Lioudaki E, Mavroeidi NG, Mikhailidis DP, Emmanouel S, Ganotakis ES. Sub-clinical hypothyroidism and vascular risk: An update. Hormones. 2013;12(4):495-506. PubMed.

17. Bonetti PO, Lerman OL, Lerman A. Endothelial dysfunction: A marker of atherosclerotic risk Arterioscler Thromb Vasc Biol. 2003;23:168-175.

18. Razvi S, Shakoor A, Vanderpump M, Weaver JU, Pearce SH. The influence of age on the relationship between sub-clinical hypothyroidism and ischemic heart disease: a meta-analysis. J Clin Endocrinol Metab. 2008;93: 2998-3007.

19. Kvetny J, Heldgaard PE, Bladbjerg EM, Gram J. Subclinical hypothyroidism is associated with a low grade inflammation, increased triglyceride levels and predicts cardiovascular disease in males below 50 years. Clin Endocrinol (Oxf). 2004;61: 232-238.

20. Winkler R, Griebenow S, Wonisch W. Effect of iodide on total anti-oxidant status of human serum. Cell Biochem Funct. 2000;18(2):143-6. PubMed.

21. Jameson L, Longo DL. Ch.-121: Paraneoplastic syndromes: endocrinologic and haematologic in Harrison's Principles of Internal Medicine. (AS Fausi, SL Hauser, DL Kasper, DL Longo, JL Longo, JL Jameson, J Loscalzo eds) $19^{\text {th }}$ Edition. McGraw-Hill education: New York, 2015: 608-613

22. Kholsa S. Ch.- 65: Hypercalcemia and Hypocalcemia in Harrison's Principles of Internal Medicine. (AS Fausi, SL Hauser, DL Kasper, DL Longo, JL Longo, JL Jameson J. Loscalzo eds) $19^{\text {th }}$ Edition. McGraw-Hill education: New York, 2015; p313-314.

23. Couch S, Krummel D. Ch.- 12: Medical Nutrition Therapy for Hypertension in. Krause's Food, Nutrition and Diet Therapy (Mahan LK, Escott-Stump S (eds.) Philadelphia, W.B. Saunders Co. (12), 2008: 865-881.

24. Derman EW, Whitesman S, Dreyer M, Patel DN, Nossel C, Schwellnus MP. Healthy lifestyle interventions in general practice Part 7: Lifestyle and hypertension. $S A$ Fam Pract. 2009;51(5):382-386. PubMed.

25. He FJ, Jenner KH, Macgregor, GA WASH—world action on salt and health. Kidney Int. 2010;78: 745-753. PubMed. 